\title{
A STEP BEYOND DIRECT AND INDIRECT DISCRIMINATION AGAINST PERSONS WITH DISABILITY METHODOLOGICAL APPROACH TO DISCRIMINATION FROM THE INTERSECTIONAL PERSPECTIVE
}

\author{
PAOLA BALANTA-COBO ${ }^{1}$
}

ANDREA PADILLA-MUÑOZ ${ }^{2}$

\begin{abstract}
This article provides a different methodological proposal to disability research grounded in the intersectional perspective since other forms of research, such as the dogmatic perspective of law, have shown limited results in terms of full recognition of people and groups exposed to multiple situations of inequality, specifically in the case of people with disability. We propose a methodological route that links disability to the intersectional perspective, and finally we assess an example of a process that accounts for the importance of a robust analysis to advance in critical understanding of this challenging and interesting field of study.
\end{abstract}

Keywords: Disability, Anti-discrimination Law, Critical Studies, Intersectionality, Social Inequalities.

Contents: I. INTRODUCTION; I.1. The intersectional perspective from a methodological approach - Key Aspects; II. PATHWAY FOR THE DEFINITION OF THE METHODOLOGICAL APPROACH; II.1. Review of the main developments that apply intersectionality and relate to disability (Step 1); II.2. Identification of the most relevant analytical criteria (Step 2); II.3. Consolidation of the methodological proposal - Presentation of the dimensions (Step 3); II.4. Application of the methodological approach (Step 4); II.5. Approach to discrimination trajectories (Step 5); III. CONCLUSIONS.

\section{INTRODUCTION}

Law is the traditional approach to the study of inequalities to which diverse groups are exposed. It adopts a dogmatic methodology characterized by positivism. Although this approach has advanced in the study of problems or situations faced by persons with disability, its responses are characterized for being undynamic. These initiatives, in the majority of cases, deal with individualistic / formalist legal problems or with direct and indirect forms of discrimination. In this sense, situations of discrimination linked to systems of inter-group oppression are set aside (Barrère and Morondo, 2011, p.17).

This paper argues that the traditional approach to research in the field of disability may be limiting the analysis, because it does not explore in depth the way in which different systems of oppression and power structures operate. It is claimed thus that the

\footnotetext{
${ }^{1}$ Doctor Candidate, Law School, Universidad del Rosario, Colombia (paolabalanta@gmail.com).

${ }^{2}$ Doctor in Juridical Science (Ph.D). Master's degree in Law (LLM), Master in European Mediation (MSc). Professor in Human Rights and Disability. Member of the Research Group on Human Rights. Law School, Universidad del Rosario, Colombia (andrea.padilla@urosario.edu.co).
} 
traditional approach protects, naturalizes and perpetuates visible and invisible systematic practices of exclusion, oppression, silencing and non-recognition (Meekosha and Soldatic, 2011, pp. 47-75).

In this context, the intersectional perspective provides both analytical and methodological elements to the study of disability in a broad and profound manner. In order to demonstrate the pertinence of this methodological approach, we review the antidiscrimination doctrine and put forward an alternative methodological proposal:1) review the main theoretical and methodological developments of researchers interested in putting intersectionality into practice, 2) select the main analytical criteria that support the methodological proposal, 3) delimit the methodological proposal, 4) apply the methodology to a documentary source related to disability, 5) describe the trajectories of discrimination that emerge as a result of putting into practice a methodology that recognizes the intersectionality of multiple forms of inequality.

\section{I.1. The intersectional perspective from a methodological approach - Key Aspects}

The intersectional perspective is presented as an epistemic perspective that offers a range of opportunities to get closer to the multiple relationships established between different axes of inequality to which collectives are exposed, including persons with disability, as a result of forms of institutional functioning or power structures that perpetuate and reproduce situations of oppression (Cho, Crenshaw and McCall, 2013, p.795; Portocarrero et al., 2014, pp. 12-43).

In this way, it becomes an approach of major relevance for the law and, in particular, for Critical Disability Studies as it allows to analyze the way in which situations of discrimination on the grounds of disability continue to exist, despite new paradigms, treaties and international and national obligations that require structural transformations.

Intersectionality has the potential to be regarded as an analytical and methodological starting point that accommodates all disciplines interested in understanding systems of oppression.

Consequently, it has consolidated as a way of analyzing the dynamics of equality and difference and how they are related to power. The anti-discrimination doctrine approaches the problem of equality and difference from single or separate axes, studying in depth the way in which structures of oppression intervene and their relationship with power, evidenced in any discipline. Hence, some of its main authors consider it to be a nodal point of inquiry, open to any field of study, regardless of the situation of discrimination under analysis, far from becoming a standardized methodological proposal or a complete theory (Cho, Crenshaw and McCall, 2013, p. 789; Yuval-Davis, 2015, pp.1$10)$. 
However, it is important to emphasize that the incorporation of the intersectional perspective has been limited at the normative and empirical level, in comparison with the way it has been incorporated at a doctrinal level, with extensive developments linked to critical race studies. Its closeness to legal and political issues, in order to influence transformations in the pre-established order, is however unquestionable for authors such as Cho, Crenshaw and McCall (2013, p.796), La Barbera (2017, p.193) or Yuval-Davis (2015, pp.1-10) who consider it a relevant scenario to address issues of Human Rights Law, Anti-discrimination Policies and Social Movements.

The link between this perspective and disability studies is unquestionable, despite the fact that it has only recently begun to be explored at a conceptual and methodological level (Arenas, 2013, p. 24). Now, those who interpret intersectionality as a perspective that has the potential to expose the complexity and dynamism inherent to disability have also dared to undertake the path of putting intersectionality into practice. Both from a broad and from a micro-sociological perspective, the complexity of social processes is exposed to reveal hidden forms of discrimination resulting from specific intersections (Angelucci, 2017, p. 16). Examples of these practices include: i) a transforming perspective to approach communities, life histories and the multiple ways in which inequalities and power structures are expressed (Larson et al, 2016, p. 2), ii) a mean to access the understanding of the connections between privileges and situations of subordination, iii) a form of recognition of the multiple ways in which power structures are expressed, in such a way that transformations are advanced from political action (Cho, Crenshaw and McCall, 2013, p. 803), iv) a way of appreciation for situated experiences highlighting their analytical and political potential in scenarios where equity and social inclusion should be a priority for people with disability (Portocarrero et al., 2014, p. 38), or v) a way to broadly understand the forms and dimensions of oppression that intersect simultaneously -most of the time in the same person with disability- and through which it is possible to understand how opportunities and exclusions are configured (Sommo and Chaskes, 2013, p. 48; Minkowitz, 2010, pp. 1-8).

Some examples of specific intersections are i) exclusion or deprivation: excluding someone from active participation in society, limiting the mechanism of institutionalization or limiting the opportunities to participate in decision making on matters that directly concern them, ii) oppression: oppressing someone, or placing them in a inferior position by maintaining of a stereotype belief about who, how and what assistance/care/support should be facilitated to them, iii) denial: denying someone the possibilities and opportunities to demonstrate and consolidate a life project because of personal interests or expectations; iv) marginalization: having different treatment and access to the enjoyment of opportunities and privileges -girls and women being exclusively destined for home care or assistance of others-, education, jobs -other than those socially and culturally predestined for people with disability.

In this sense, the methodological proposal we are developing constitutes an opportunity to critically examine and analyze the social dynamics in which people and communities with disability live and the trajectories, systems and power structures in 
which disability is configured, which would be unimaginable for another historical moment or under the traditional view of law.

\section{Pathway for the Definition of the Methodological ApProach}

Here are the five (5) steps that have been taken to consolidate the methodological approach. Step three (3) is characterized by a broad description of the constitutive elements. Figure No. 1

\section{PATHWAY FORTHE DEFINITION}

\section{OF THE METHODOLOGICAL APPROACH}

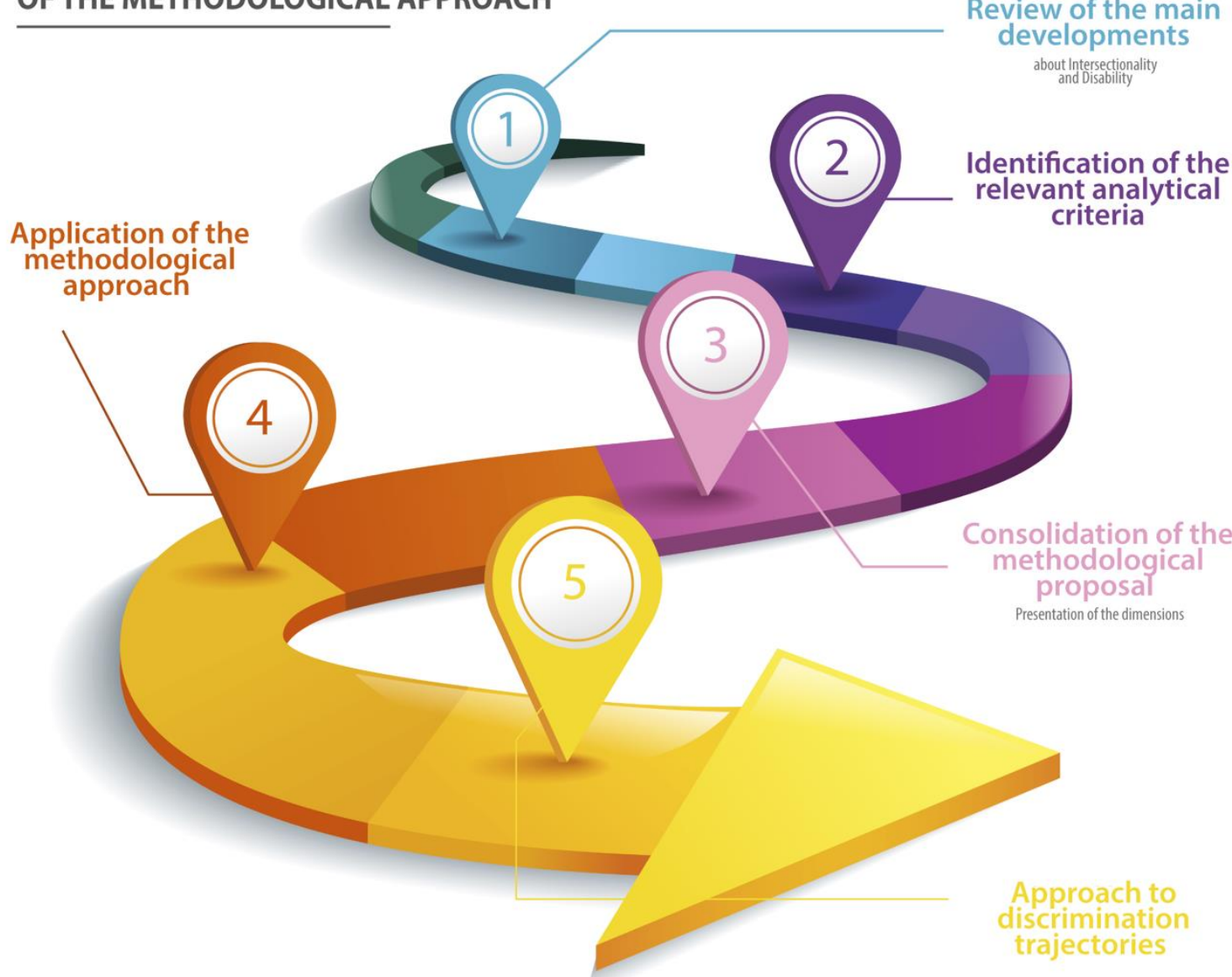

Figure No. 1 Pathway of the Methodological Approach (own elaboration). 


\section{II.1. Review of the main developments that apply intersectionality and relate to disability (Step 1)}

The first step was to identify, review and analyze the documentary information; doctrine, jurisprudential sources, legislation and reports of the United Nations related to disability which specifically approach intersectionality. This search was based on the work done by Cho, Crenshaw and McCall (2013, p.796), who define intersectionality as an analytical and methodological disposition to delve into the structural dimension of problems related to equality and difference; and raise the importance of looking at ways to bring intersectionality into action.

The selected information sources resulted from the integrated search system of the Universidad del Rosario through the EBSCO database, using the descriptors "disability", "intersectionality" and "methodology" in Spanish and English. Using the findings of the main authors or referents in the subject of intersectionality and specific developments in the subject of methodology and disability, and despite the limited sources available, we proceeded to delimit the search by author and explore other sources of information such as: official pages of the authors where they present updated academic production, books and book chapters. Additionally, we used Google Academic for those cases in which the bibliographic source was not easy to obtain.

Thus, it was possible to obtain developments located in various fields of study such as: Law (La Barbera, 2017, pp. 191-198; Naciones Unidas, 2017; MacKinnon, 2013, pp. 1019-1030; Barrère and Morondo, 2011, p.15-42 ); Sociology (Angelucci, 2017, pp.118); Social and Political Sciences (Yuval-Davis, 2015, pp.1-10); Public Health (Larson et al., 2016, pp. 964-969); Law and Political Science (Cho, Crenshaw and McCall, 2013, pp. 785-810).

Similarly, we gave priority to developments that addressed intersectionality and analyzed disability from more than one axis of inequality (Lawson, 2011, p. 47; ZotaBernal, 2015, p. 73; Meekosha and Shuttleworth, 2009, p .62; Portocarrero et al., 2014, p. 38; Sommo and Chaskes, 2013, p. 47-59; Arenas, 2013, pp.23-45).

\section{II.2. Identification of the most relevant analytical criteria (Step 2)}

The documental review became the main input to define the analytical criteria that would be incorporated in the methodological proposal. The definition of these criteria made it possible to outline the key aspects to approach disability studies and to move towards "intersectionality in action" (Cho, Crenshaw and McCall, 2013, pp. 785-810) giving priority to social dynamics and relations between axes of inequality; without this implying unique "formulas" or rigid approximation schemes.

Next, we describe the aspects that, in the documental review from the criteria of practical and theoretical relevance, were recurrently incorporated and analyzed in the diverse works that include the intersectionality perspective and simultaneously have contributed with the objective of configuring a flexible and dynamic approach to the study 
of disability. These aspects became the guiding elements of the proposal that will be presented later.

\section{A. Characterization and contextual location of the situation being analyzed}

This is a key aspect which aims to move away from essentialist and universalist approaches that omit the particularities of the social reality.

For various scholars of the intersectional perspective, it is fundamental to analyze the complexity and dynamism of power relations and the way in which social constructions that emerge from histories, cultures, beliefs, immersed in social, economic and political contexts, determine the particular and interconnected form as they operate from diverse axes of inequality (Lawson, 2011, p. 47; Yuval-Davis, 2015, pp.1-10; Erevelles and Minear, 2010, pp. 127-145).

In this form, understanding power structures and the ways in which privileges are defined will be possible if the analysis is accompanied by the recognition of the dynamics of interaction that occur in sociopolitical, cultural contexts, moments and specific spaces (Cho, Crenshaw and McCall, 2013, p. 807).

For this reason, this methodology proposes situated or contextual analysis as a fundamental aspect of approximation; recognizing its flexible and dynamic nature, as well as the potential to reveal particular inequalities and/or resistances in certain contexts.

\section{B. Analysis of the life experiences of people who are part of the situated context} object of analysis

This aspect widens the perspective of how each person experiences personal, social, political, and/or normative situations.

This aspect is incorporated into intersectional analyses, with the aim of guiding and deepening interpretations and reflections on their identities, the social construction of inequalities or the effects of such inequalities (Portocarrero et al., 2014, p.12-43); as well as on the life experiences that are configured in a particular way, as different axes of inequality converge simultaneously (Lawson, 2011, p. 49; Sommo and Chaskes, 2013, p. 48).

\section{Particular intersection established between more than one axis of inequality}

This aspect identified by the authors is a broad approximation of the intersectional perspective, and consists of the attempt to recognize each one of the axes of inequality that are involved in the situation under study, as a prior condition to identifying the particular intersection in which each axis is involved.

However, this differentiation of the axes, as warned by Barrère and Morondo (2011, p. 40), is not meant in any way to fragment or individualize the analysis nor to 
erase the political character of the inequality relations studied. From an intra categorical methodological approach (McCall, 2005, pp. 1771-1800; Angelucci, 2017, pp. 1-18) it is argued that what is intended to be accounted for are precisely the categories or axes of inequality which are closely related to the situation or "case" study, and thus the heterogeneity and diversity present in the various contexts studied.

It is important to identify the different axes that affect inequality director indirectly because it puts intersectionality into practice, allowing it to work strategically with categories or axes relevant to the case of study, which contribute to identify practices, symbols, institutions and structures that reproduce meanings, roles and social identities (Angelucci, 2017, p. 6).

\section{A particular relationship established between more than one axis of inequality}

The second aspect seeks coherence between the principles and foundations of the intersectional perspective, and involves understanding the particular way in which the axes relate in temporal and social contexts, defining and energizing the power relations and inequality structures that generate and perpetuate discrimination (Cho, Crenshaw and McCall, 2013, p. 789; Angelucci, 2017, p. 13).

This intersection is configured from axes that are deconstructed and created from a new and particular intersection in order to reduce possible essentialisms (Angelucci, 2017, p. 11).

However, some authors suggest that the particular relationship between the various axes of inequality should be analyzed as the recognition of a fluid and the changing relationship and intersection of it. This means the intersection does not exclusively depend on the categories or axes of inequality, but on the way in which the axes of inequality -sometimes not so dissimilar among them- are related (Cho, Crenshaw and McCall, 2013, p. 797; Yuval-Davis, 2015, pp. 1-10).

\section{E. Identification of systems of oppression and power structures, through trajectories of inequality}

The last aspect, and also the most challenging, strives to identify how power structures work, since they are acting in a different manner and their recognition can be diffuse, and they are interwoven, naturalized, formally justified and established in political, social and institutional contexts that have withstood the passage of time and have rarely been questioned or critically reviewed.

One of the main objectives of intersectionality is to account for the way in which power structures operate and relate to each other in order to produce hierarchies, in unlimited combinations of relationships between situations of inequality (Cho, 2013, p. $385)$. 
Thus, this dimension emphasizes on identifying systems of oppression and power structures, through trajectories of inequality, since these represent and show dynamic forms in which situations of discrimination, disadvantage and/or transformation are generated.

For this reason, we refer to the notion of trajectory proposed by Caicedo and Porras Velasco (2010, p. 38) who state that being able to identify and recognize differences - as in the case of disability -implies a complex approximation to the multiple situations that happen over time; this way it is possible to account for a social constellation of inequalities and distinguish both interior differences and exclusions, as well as those that position in places of respect for difference.

\section{II.3. Consolidation of the methodological proposal - Presentation of the dimensions (Step 3)}

In steps 1 and 2, we have presented the dimensions that incorporate the main analytical and methodological considerations. These dimensions, as a whole, aim to explain how various situations of inequality converge, intersect and generate trajectories of difference which consequently cause discrimination. The dimensions are presented separately in order to facilitate the understanding. They are represented in a cyclical image (see figure No.2) as we suggest they be incorporated into the analysis in an interrelated and dynamic manner based on the analytical interests and type of situation to be explored since their approximation is more related to a process than to a linear sequence.

It begins with an initial logical sequence in order to preserve the internal coherence between dimensions; it is understood that it should not be assimilated toa rigid or hierarchical structure but used as a possible approach while simultaneously remaining open to new approaches. In our example we apply it to explore issues related to disability.

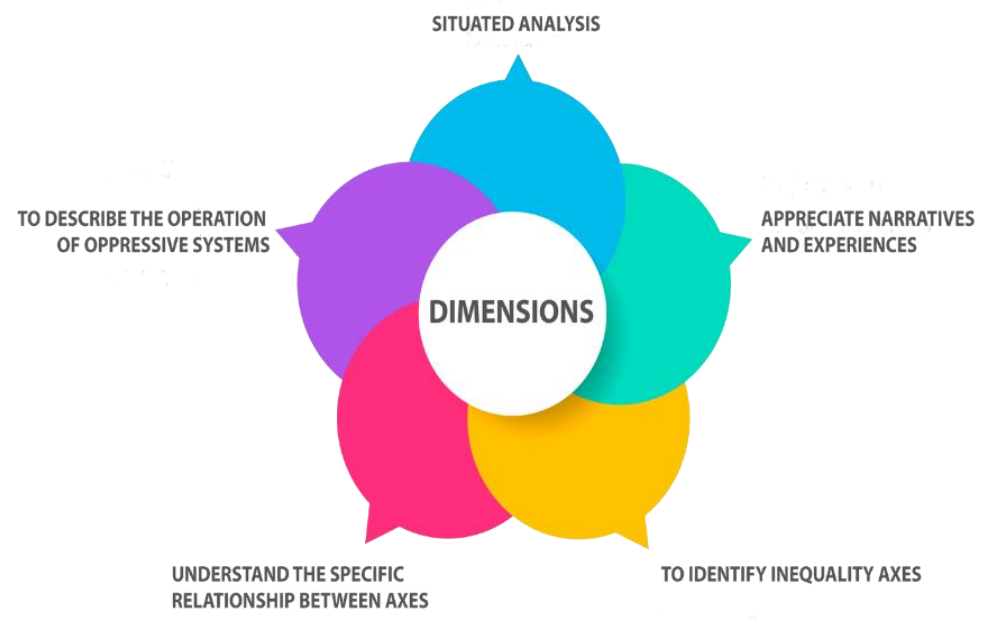

Figure 2. Dimensions that constitute the methodological proposal to analyze disability from an intersectional perspective (own elaboration). 


\section{A. Situated analysis - defining the situation under study}

This dimension proposes a flexible and dynamic approach to the multiple social, economic and cultural contexts in which different situations of inequality are presented. This way, it becomes the starting point to characterize, analyze and delimit the field of study of intersectionality.

This dimension emerges from the intersectional perspective as a result of the importance attributed to the characterization and contextual location of diverse situations analyzed here, such as: experiences of people with disability, interpretations, decisions, privileges and exclusions coming from institutions, as well as the scope of projects, activities and anti-discriminatory measures created to protect this group. The purpose of this is to bring upon a critical approach to historical situations and contexts and simultaneously, reduce the level of uncertainty and ambiguity that is sometimes attributed to the intersectional perspective as a difficult practical approach where multiple factors come together.

We propose to begin by identifying the context and the situations under study in order to understand the specific characteristics of object of analysis, its structural and contextual nature, and the situations of inequality. It is frequent to approach situations of discrimination that are more visible or that are more frequently related to power structures. By contrast, our proposal here is to sharpen the focus and deepen the identification of aspects and situations that participate indirectly but are seldom explored. These aspects and situations are decisive due to their role in the maintenance and naturalization of situations of discrimination.

Therefore, some aspects suggested for situated analysis are:

- $\quad$ The situation under analysis is interpreted, justified and conceptualized on a criteria based on respect and dignity, not discrimination on any reason against people with disability.

- When defining and analyzing the situation, it is important to locate it and contextualize it in order to take account of the specific particularities and complaints of people and groups of people with disability, moving away from universalist or general approaches.

The contextual analysis includes an examination of the relationship between the studied situation and social determinants of inequality frequently associated to situations related to people with disability (socio-economic and political context, multidimensional poverty, informal work, environmental factors, limited access to health services and quality care and inclusive education, and in general type of resources available in the environment for the full enjoyment of rights). characterized.

Particular, emerging situations of inequality are identified and

- $\quad$ The specific claims of persons and groups of people with disability broadly analyze the social, geographic, economic, political and cultural conditions in which they participate and coexist. 
A broad and critical approximation of the intersectional perspective will imply the fulfillment of most of the criteria proposed for each dimension. However, cases where some of the criteria are not identified should be considered as part of the analytical process, since we must be aware of aspects that need to be further explored in order to reveal situations of inequality and trajectories that require transformation.

\section{B. Appreciate narratives, experiences and ways in which people's voices are recognize}

This dimension is characterized by the appraisal of the different voices, experiences, forms of representation and transforming capacity in the situated contexts where people and collectives are located. In this sense, it offers analytical elements to reveal the existence of broad or narrow approximations of the diverse forms of participation and opportunities to listen to in order to understand the experiences that happen in the different life ways.

To explain the political nature and transformative power of the intersectional perspective, there needs to be a broad and open recognition of the voices of those directly exposed to situations of inequality. This will take us to understand how people with and without disability interpret, coexist and live through the various power structures, as well as what mechanisms, processes, services and policies do not always guarantee the full enjoyment of their rights and claims.

Consequently, this dimension recognizes the importance of analyzing experiences that contribute to identifying the scope of those mechanisms defined by institutions or decision-makers. In this phase, the stories are analyzed and reviewed in order to recognize the leading role of people and groups exposed to situations of inequality seeking to account for the way in which capacity or incapacity is presumed, how various forms of protection are excluded, included, justified and naturalized.

In general, it is proposed as a dimension that critically analyzes how to promote the recognition of voices, becoming an analytical tool to make visible spaces for active participation or, on the contrary, the prevalence of universalist, essentialist and heteronormative proposals that perpetuate discriminatory practices by silencing their voices.

Thus, some aspects that are suggested for voice recognition are:

- Identify the type of specific approach, based on the recognition of epistemological positions that guide proposals, programs, projects or activities; seen from an intersectional point of view that recognizes particular relationships or, on the contrary, from a general point of view, centered on disability or illness in which asymmetrical power relations predominate.

Recognize the mechanisms and measures designed by institutions -such as accessibility and reasonable adjustments- to identify particular needs and alternative 
forms of communication that include all types of people with disability without discrimination.

- Understand the various forms of representation towards people with disability and groups, moving away from classifications, hierarchies or essentialist views. diversity.

- $\quad$ Support approaches aligned with human rights, dignity and respect for disability.

Analyze the multiple and heterogeneous forms of approaching people with

- Value experiences and presume the capacity of agency, self-determination or transformational power.

- Approach alternative mechanisms of participation and recognition of the voice and the will of people with disability.

- $\quad$ Explore how the expression of a will, an interest or an expectation of a person with disability is visible.

\section{To identify inequality axes linked to the object of study}

This dimension is characterized by the differential recognition of axes of inequality that are explicit or that have been widely analyzed, as well as the recognition of axes that have not been dealt with in the framework of an analysis situated in the context under study.

This dimension precedes the understanding of the intersection between axes of inequality and consequently, according to the methodology proposed, appraise information to access the broad and critical understanding of the multiple and unique forms as they manifest and express situations of inequality.

In order to account for the configuration of each axis we must enhance an intersectional analysis, allowing to characterize, create and demonstrate the complex and dynamic form in which the axes interact. Additionally, it reveals personal, temporal, historical and social situations and contexts in which power structures have been consolidated, naturalized and homogenized. Nevertheless, it is a dimension that can cause controversy because it can be understood as a reductionist or essentialist approach, but it is expected to be understood as a dimension that contributes to the complexity of the analysis, recognizing its dynamic and open nature from the construction of the axes that participate in the intersectional analysis.

Accordingly, some criteria to consider for the analysis of each axis are:

- $\quad$ Reference the dimensions previously studied (situational analysis and recognition of people's voices) and turn them into an input to name and clearly identify the practices, symbols, institutions and structures that directly and indirectly have been used to represent disability.

- Review the configuration of institutional structures; in cases related to dignity and in cases related to traditional forms of discrimination where power structures based on overprotection, conditional participation are insufficient and limited in 
recognizing a legitimate way in which the expectations and preferences of people with disability can be expressed.

- $\quad$ Analyze the way in which situations of inequality are naturalized through mechanisms, measures or actions, defined and presumed to be done to guarantee and access physical and mental health services, education, training for work, social participation, independent living, among others.

- Identify practices related to the support / care and dignity, or actions based on protection, charity or compassion. disability.

- Study the privileges, priorities and exclusions specifically on the basis of

\section{To understand the specific relationship between axes of inequality.}

This dimension is proposed in order to account for the type of particular intersection that emerges as a result of the relationship between axes.

Here it will be possible to characterize a new and intricate form of inequality, based on the delimitation of the axes, the recognition of personal and contextual experiences and the understanding of the characteristics of the situation being analyzed.

To explain the particular form of inequality from the intersectional perspective, the later cannot be understood as the sum of axes that operate in a separate manner, but as a close relationship between axes built in order to create a new relationship. The intersection that is configured will allow us to analyze both the conditions of disadvantage and oppression, as well as the forms of resistance. This will account for the political nature and transformative interest of the perspective.

This dimension turns out to be very powerful and less evident than other methodological approaches to advance in the understanding of particular forms of inequality.

Therefore, some criteria to analyze the particular intersection between the axes related to disability are:

- $\quad$ Reveal the intersection between axes emphasizing the discriminatory practices that still persist and sometimes it is difficult to change due to the cost that in terms of power and structural transformations of the institutional order represents.

To analyze in an interrelated way emerging axes or few times included in the proposals defined by the institutionality.

- $\quad$ Identify and relate emerging axes with the purpose of creating particular intersections that in most cases take place in the same person with disability. This situation is intensified according to the characteristics of the context, systems and structures that determine what should or should not be done, the places that should be occupied, the disposition of diverse forms of participation close to the interests of third parties or linked to systems of oppression that insist on locating people with disability in places of subalternity and oppression. 
- $\quad$ An example of the foregoing is the rarely explored intersection between axes of inequality to which people with intellectual disability are exposed. Through these intersections it is possible to account for the complexity of their situation and reveal how power structures function through axes related to it: 1) the type of support (based on overprotection or autonomy); 2) the way in which decision-making is conceptualized (dependent, independent); 3) forms of participation (extremely limited due to confinement or broad through the promotion of conditions for independent living); 4) access to services (for all or based on priorities); and 5) exclusions and privileges according to sex, gender, race, geographic location, educational level, and others.

\section{E. To describe the operation of oppressive systems}

This dimension analyzes the particular relationship of inequality that is framed in power structures and systems of oppression that have generated and perpetuated it.

Its purpose is to make visible diverse situations of inequality, their complexity, the way these structures are installed and naturalized in the personal, social, political, juridical and institutional context.

It is also an opportunity to identify the type of structural transformations that could have an impact on the elimination and/or reduction of the effects of various forms of discrimination and inequality towards people and groups with disability.

Based on the foregoing, this dimension proposes the analysis of trajectory, as a representation of the framework between structures and situations of inequality, identified in the previous dimensions.

This analysis is proposed as a methodological resource to account for the process of how structures of discrimination and inequality are established, revealed and reproduced, at a structural, political and discursive level, based on the presumption of incapacity, biomedical approaches, or based on classifications, etc.

Regarding the way to face the challenge of revealing systems of oppression and discrimination, some authors suggest analyzing the tensions represented in power structures, through the analysis of laws, policies, decision-makers, institutions, beliefs and stereotypes (Yuval-Davis, 2015, pp.1-10).

Another way has been the review of claims and critical approaches from the human, social and health sciences, activists, collectives and social movements, who, for decades, have been in charge of highlighting the predominance of actions, value systems and explanations, which instead of recognizing and valuing difference, perpetuate practices that invalidate, exclude and deny people with disability. This can be evidenced through paternalistic, reductionist approaches that deny spaces for participation and, consequently, threaten the full enjoyment of their rights (Lawson, 2011, p.47). 
It is in this context that the idea of representing systems of oppression through trajectories of discrimination arises, due to the intricate and sometimes subtle form, as throughout history they have been installed from diverse approaches to disability (medical-rehabilitating, social, rights, others). Consequently, we move away from models of trajectory delimited by steps or lineal paths, to approach the interplay between axes and unlimited life experiences of people with disability (Sommo and Chaskes, 2013, p. 56).

Next, a series of criteria to be considered in situations related to disability and which can be evidenced in discourses, beliefs, imaginaries, or stereotypes and practices.

About the discourses:

- Discourses, interpretations and justifications in which people with disability are situated in a position of inferiority are critically analyzed and submitted to discussion.

- It incorporates updated and obligatory normative developments for the states in which the material guarantee of the rights predominates and it acts in coherence emphasizing the economic, social and cultural rights.

- The analysis of the situation recognizes the naturalized way in which diverse structures and hierarchies function, reproducing and perpetuating inequalities and discrimination based on disability.

- $\quad$ Expressions are reviewed and criticized, including political and normative discourses in which only a nominal reference is made to the supposed interest in the guarantee of rights or non-discrimination.

- The analysis of the situation gives account of the presumption of capacity, spaces for active participation and rejection of discourses in which incapacity is presumed and places people with disability in a situation of subalternity.

About the beliefs, imaginaries, or stereotypes:

- In the provision of services, asymmetrical forms of relationship and participation are revealed, which places people with disability at a disadvantage.

- Beliefs that privilege approaches from traditional models, centered on assistance, rehabilitation, biomedical approach or from interpretations that account for traces of models that place people with disability in asymmetrical, subaltern and unequal positions are subjected to discussion and revision.

- $\quad$ Alternative measures or precedents are identified within the field of law that contribute to transforming systems of oppression by being based on the human rights approach and dignified treatment.

About practices:

- Actions that are justified in the interest of protecting are subject to discussion and review, but when critically analyzed they realize that such "protection" and "overprotection" makes invisible and natural measures against non-discrimination and the recognition of life projects and decisions tailored to each person.

- It rejects and questions the effectiveness and claims of protocols and standardized procedures, based on scientificity. 
- $\quad$ Traditional institutional practices are unveiled that propose general forms for the provision of services (leaving aside specific measures required for the broad participation of all persons with disability).

The measures defined for the transformation of the situation recognize the beliefs, personal, social, environmental, political and linguistic factors of people with disability.

- $\quad$ The measures proposed to resolve the situation or problem under analysis take into account the diversity of economic, social and cultural contexts in which people with disability live and interact.

- The mechanisms defined have the purpose of promoting the active participation of all people, considering their level or intensity of support required.

- $\quad$ The use of criteria for the classification, categorization and distinction between persons is discussed, which naturally excludes, prioritizes and accounts for the heteronormative idea that is expected to be represented and recognized with respect to disability.

- $\quad$ Measures, activities and programs are discovered and made explicit in which it is almost imperceptible how the experiences and voices of people with disability have been valued and incorporated.

- $\quad$ The marked interest in the observance of priorities defined by institutions or decision-makers without including the needs and claims of people with disability is critically analyzed.

\section{II.4. Application of the methodological approach (Step 4)}

In order to implement the methodology, we propose a matrix (see annex No. 1), which will guide future analyses conducted by people or institutions interested in the issue.

However, by way of example, we will now analyze a document that, although it incorporates the intersectional perspective in some sub-sections, does not manage to account for the functioning of oppressive systems and power structures and therefore becomes an input to represent the trajectories of discrimination and inequality.

The example selected is the report of the United Nations Special Rapporteur on people with disability (ONU, 2017), which reviews the issue of support and recognizes the voices of hundreds of people, based on the systematization of situations of inequality (known and emerging) reported by states members, collectives, organizations, people with disability and their representatives. Example presented in table form in order to facilitate understanding. 


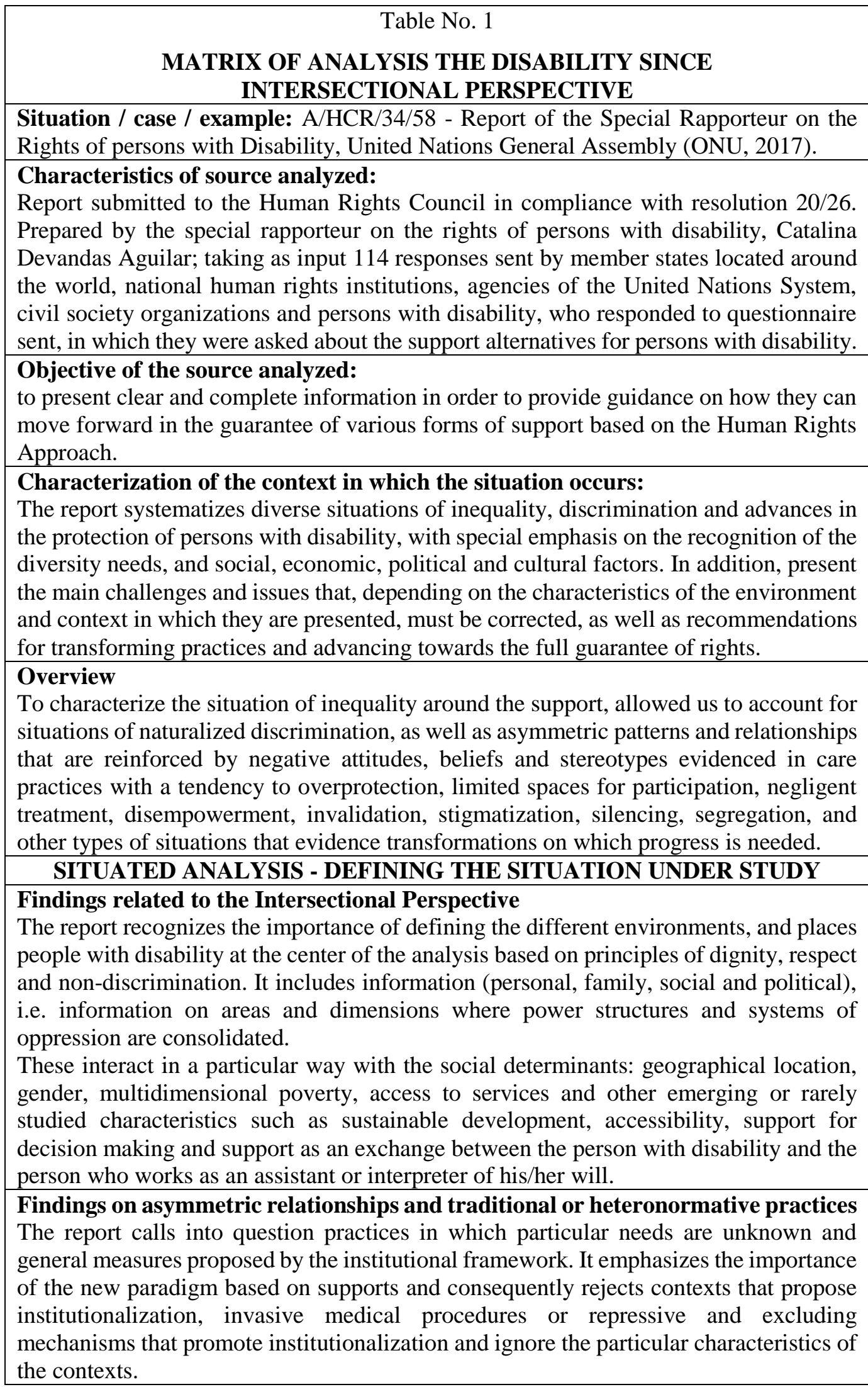




\section{APPRECIATE NARRATIVES, EXPERIENCES AND WAYS IN WHICH PEOPLE'S VOICES ARE RECOGNIZED \\ Findings related to the Intersectional Perspective \\ The report is based on the voices, opinions and self-determination of the people with disability. The information obtained makes it possible to identify particular relationships between the various situations to which people with disability are being submitted. \\ One aspect to highlight is the way in which supports vary according to personal factors, gender, age, socioeconomic situation and origin; in this way the need for recognize of diversity, interests, motivations and other forms of representation of disability is justified.}

Findings on asymmetric relationships and traditional or heteronormative practices The report considers the importance of transcending traditional approaches, focused on disease, on the presumption of disability, or on third parties making decisions, replacing or silencing person with disability voices.

This becomes a way of recognizing people as full subjects of rights, without privilege the voice of those who have historical and social assumed the role of caregiver or has been perpetuating asymmetrical power relations.

\section{TO IDENTIFY INEQUALITY AXES LINKED TO THE OBJECT OF STUDY}

\section{Findings related to the Intersectional Perspective}

Although this dimension presented some challenges for the identification of emerging axes, to have information gathered in the previous dimensions facilitated their identification.

The report also deal axes with which disability has traditionally been represented, such as: dependency, overprotection, conflict of interests, isolation, displacement, conflict situations, immigration, loss of freedom, communication and accessibility. It also allowed the identification of the emerging axis related to support and characterized by the denial of support to people with disability, which as a result of analyzing the lack and marginal provision of support, which limits the possibilities of carrying out daily activities, participate in society, and leads to invisibilization or negligent treatment.

Findings on asymmetric relationships and traditional or heteronormative practices The report propose the necessary transformation of protectionist practices, as well as deficiency-based representations of disability, which must be eradicated to the extent that naturalized and perpetuate asymmetric relationships and discriminatory situations. It questions situations of discrimination such as: reduced autonomy, general support, presumption of incapacity, denial of spaces for political participation, physical and attitudinal barriers, lack of support resources, as well as limited budget allocations that limit the full enjoyment of all rights under equal conditions.

\section{TO UNDERSTAND THE SPECIFIC RELATIONSHIP BETWEEN AXES OF INEQUALITY}

\section{Findings related to the Intersectional Perspective}

The report describes some of the situations it approaches from an intersectional perspective, as a way to move towards proposals aimed at the dignified treatment and recognition of the difference of persons with disability.

Specifically, a section is proposed to account for intersections related to women and girls, children and the elderly. Although it incorporate inequality, the reference to the configuration of a particular type of inequality or intersection, the product of the relationship between the axes, is not explicit.

On the other hand, there is the category of disadvantaged groups that includes (indigenous people, ethnic minorities, people with HIV/AIDS, migrants, displaced person, refugees, prisoners) that, when reviewed from an intersectional perspective, 
would require particular analyses due to the contextual, social and political nature in which each situation is circumscribed.

However, from the application of the criteria proposed, the gender axis was associate with issues related to family structure, geographic location, race, class, age, religion, or income level, and thus it was possible to represent the intersection in a much more complex way.

In other sections, the report alludes to accessibility, the lack of consideration of support for decision-making and reasonable adjustments, and links it to axes such as age, sex, gender, access to education; thus, it was possible to infer particular intersections that account for much more significant negative effects than when analyzed separately. However, the report does not delve into this type of relationship.

Finally, emerging intersections were identified related to the support provided exclusively by families that perpetuate stereotypes, which is consolidated from the deconstruction of inequality axes: 1) the level of dependence of both family members and the person with disability, 2) the limited capacity to make decisions regarding the type of support required, 3) dysfunctional social relations, 4) low income level.

Other intersection is the lack of accessibility for children, for whom a particular type of intersection is disproportionately evident due to 1) the provision of general support for communication, which is not sufficient to resolve the difficulties they have in speaking or when they do so in a limited way, 2) the lack of economic resources to access support or alternative forms of communication, 3) residence in rural or remote areas, which makes it difficult to mobilize to places where support or services are provided, 4) limited access to social services, 5) limited or no access to the education system.

Findings on asymmetric relationships and traditional or heteronormative practices The report rejects traditional or separate analyses that fail to account for how asymmetric relations and power structures are maintained.

It also allows us to question institutional practices such as the exclusive care given to families or the denial of support based on the justification of budgetary control; situation, when not analyzed in an intersectional manner, fail to account for the way in which the situation is exacerbated in a single person, placing him or her at a greater disadvantage.

\section{TO DESCRIBE THE OPERATION OF OPPRESSIVE SYSTEMS}

\section{Findings related to the Intersectional Perspective}

For the analysis of this dimension, the report is based on the Convention on the Rights of Persons with Disability - CRPD, which acts as a normative instrument to promote spaces for active participation and reject presumptions of incapacity.

In general terms, the report does not provide as much information compared to that gathered in the previous dimensions. However, the main finding refers to the identification of existing tensions between general institutional practices, thus maintaining hegemonic structures of power, which goes against the claim of particular support, as a way to promote inclusion and reduce situations of inequality.

The report also made it possible to reveal the subtle but real form, as some exclusions are justified, through regressive measures, which leads to particular demands being neglected or invisible; such is the case of limited access to community support services that require personal assistance, services absent in rural areas or remote places.

Findings on asymmetric relationships and traditional or heteronormative practices A valuable finding refers to how most states continue to maintain exclusionary practices through measures that fail to comprehensively meet the required support needs. This is accompanied by a marked preference and naturalization of welfare protection measures, paternalistic and individualized, which maintain structures of inequality and are little related to critical approaches that seek to admit and resolve intersectional situations. 
A STEP BEYOND DIRECT AND INDIRECT DISCRIMINATION AGAINST PERSONS WITH DISABILITY METHODOLOGICAL APPROACH TO DISCRIMINATION FROM THE INTERSECTIONAL PERSPECTIVE

Another finding of the continuous functioning of oppressive systems was the type of interpretations, justifications and measures proposed by the institutional framework in which only in a nominal manner is the importance and value of the voice of persons with disability recognized, but in a material manner, the measures or strategies that fulfill this objective are absent.

In this manner, it was possible to account for the analytical potential of the proposed dimensions from an intersectional methodology, allowing a critical analysis of alternative and systematic contemporary social issues such as disability. Annex No. 2 presents a series of key questions that, together with the criteria proposed for each dimension, can be used as a reference to guide and extend subsequent analytical exercises.

\section{II.5. Approach to discrimination trajectories (Step 5)}

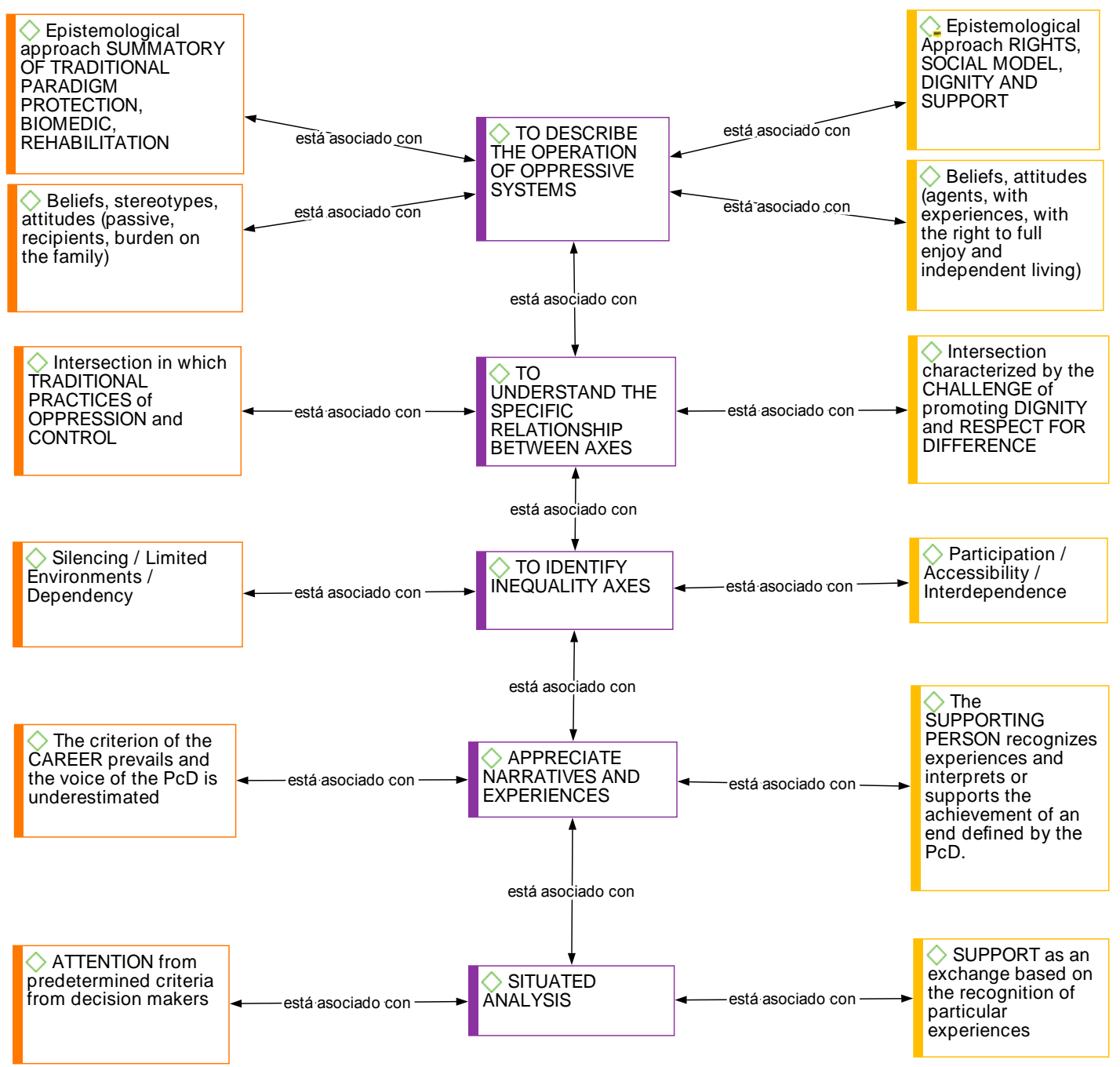


This step is developed from the application exercise previously elaborated in table 1. Starting from the identified findings and using the Atlas ti software as a tool for qualitative analysis, the relationship is established between the dimensions of the proposed methodology (centre column, starting with the perspective situated). Each dimension is associated with a code represented in a box, which are located side by side (left and right).

This exercise seeks to represent the trajectory that is configured from the relationship between dimensions and codes, allowing an approach to the intricate and unsuspected ways of functioning and configuration of the structures of power and inequality. To this end, it proposes an exercise of contrast between asymmetric relations and traditional or heteronormative practices (codes located on the left), and measures and representations aimed at reducing the gaps and situations of inequality evidenced from the analysis from the intersectional perspective (codes located on the right).

With respect to the functioning of power structures (codes located to the left), traditional discourses, beliefs and practices were identified that explicitly and implicitly account for systematic and historical situations of inequality to which groups and persons with disability have been exposed.

In particular, absences were identified in the analysis located to understand the situation under analysis, and on the other hand, approaches of attention based on standards and general modes of intervention were prevalent; added to this, the trajectory allows to account for a progressive and subtle form of subordination in which the criterion of a third party or caregiver is the one that is weighed and, therefore, the voice as well as the experiences of the person with disability, are not the priority. In this way, a trajectory of discrimination with limited transforming or emancipatory potential begins to be consolidated due to the predominance of inequality axes characterized by silencing, situations that generate dependency and environments that restrict autonomy, that maintain positions of subalternity, generating particular relations of inequality in which practices of control, discrimination and oppression prevail. Finally, by reviewing the power structure and system of oppression that characterizes this part of the trajectory, it is possible to account for approximations, beliefs, stereotypes and attitudes, in which persons with disability are seen as passive, recipients of attention and sometimes a burden on the family and institutions; approximations that are largely the result of cultural and imaginary constructions, close to paradigms based on protection, illness or deficiency.

In contrast, the analysis of the trajectory configured on the right approaches new epistemological developments, in relation to the paradigm of support and rights approach, allowing to account for the type of transformations required in the form of inclusive practices, presumption of capacity, and establishment of beliefs and imaginaries around self-determination and alternative forms of participation of all people -without exception-in the same way, it makes visible the type of transformations or turns required to advance towards the full recognition of rights. 
In addition, it highlights the importance of support rather than attention, and consequently raises issues related to other forms of relationship in which it is possible to exchange with the person with disability, where it is fundamental to recognize contexts of participation and, therefore, instead of heteronormative and universalist approaches, what is raised is the emergence of experiences located in particular contexts. Configuration that also provides elements of significant value to account for the progressive importance of participation and recognition of the voices of people with disability, through the figure of the support person or sometimes understood as a personal assistant, who will focus on interpreting and supporting the achievement of objectives and priorities.

In this way, a process is configured with emancipatory visions, which can be seen through axes related to participation, accessibility and interdependence. Axes that, when analyzed in an intersectional manner, challenge the status quo that naturalizes and maintains exclusionary practices. It is also possible to reveal a system of beliefs, attitudes and practices in which the recognition of people with disability as agents is predominant, with the right to the consolidation of independent life projects. Approaches that seek to transcend the normative and formal guarantees and are consolidated as approaches that promote material forms for the real exercise of rights.

In this way, it is possible to appreciate tensions and movements interwoven in trajectories of discrimination and inequality, which represent the complexity of the social, political and cultural phenomena to which people with disability are exposed on a daily basis and on which it is necessary to continue exploring, maintaining a critical and selfcritical stance, which allows us to reveal the multiple and innovative ways in which situations of inequality or transformation are inserted and configured.

Finally, focusing on the above, we can conclude that the trajectory identified here, although it contributed to the example and fulfillment of the scope of this article, is an exercise that, based on subsequent analysis, we hope will give rise to other types of analytical configurations around the multiple issues that make up disability, which will also result in the consolidation of the proposal.

\section{Conclusions}

Discrimination immersed in situations of inequality and systems of oppression, is a fact that exists and, at present, we can find it systematically in various groups, including people with disability. For this reason, incorporating in the analysis the main constitutive elements of the intersectional perspective in relation to disability became a proposal that allowed us to broaden the vision and advance towards the recognition and identification of specific actions required for eradication or structural transformation.

However, taking on the challenge of drawing up a methodological proposal to put intersectionality into practice, in addition to allowing a broad and systematic analysis of situations that directly and indirectly influence the configuration of disability, became an alternative and systematic way of approaching the various forms of discrimination on the 
grounds of disability, moving progressively away from approaches that privilege individualistic or separate views of social, economic, political and cultural situations that, as we could see in the trajectory of discrimination represented, are factors that are always present and have a determining influence.

This is how this article becomes an analytical exercise that, in addition to allowing the recognition of the way in which new viewpoints to inequality, discrimination and the recognition of people with disability emerge, contributes to new approaches from critical studies of disability.

Additionally, it highlights the way in which it was possible to demonstrate the field of action of intersectionality in matters related to disability, transcending the analysis of axes or categories related to gender to give way to emerging situations that perpetuate situations of inequality and discrimination. In this way, it is hoped to have been able to show the pertinence of the intersectional perspective for the analysis of disability, confirming that it is an open and fertile field of study.

This is how the intersectional approach is proposed as a tool for defining, justifying and critically discussing existing anti-discriminatory measures or mechanisms that leave aside complex situations of inequality. Therefore, it becomes a mechanism to continue systematically analyzing the multiple and differentiated experiences, as well as the identification of intricate relationships that are woven into the various social phenomena related to disability.

With respect to the dimensions proposed from the key aspects identified in the literature, the developments of reference authors on the subject stand out, with which it was possible to configure this proposal and account for the persistence of inequalities and systems of oppression that, as could be observed in the analysis carried out in the United Nations report, continue to be neglected, naturalized and, therefore, need to be transformed and exposed in order to undertake structural transformations.

Finally, this analytical exercise leads us to conclude on the necessary task of continuing advancing in the consolidation of methodological proposals that from diverse disciplines are interested in carrying intersectionality to action in order to critically analyze the multiple and diverse contemporary social, political and legal challenges. We hope that this article will, to some extent, contribute to the delimitation of a possible route to continue advancing in this sense.

\section{REFERENCES:}

Angelucci, A. (2017) From Theory to Practice. The Intersectionality Theory as a Research Strategy [online]. Available at: https://www.semanticscholar.org/paper/FromTheory-to-Practice-.-The-Intersectionality-asAngelucci/c49f4c86dce4c3740ad2f911788cb602b8ca5135 (Accessed: 16 mayo 2019) 
Barreré, M.A. and Morondo, D.(2011) Igualdad y Derecho Antidiscriminatorio.Subordiscriminación y discriminación interseccional: elementos para una teoría del derecho antidiscriminatorio. Anales de la Cátedra $\begin{array}{llll}\text { Francisco } & \text { Suárez, } & 45 & \text { [online]. }\end{array}$ at: https://revistaseug.ugr.es/index.php/acfs/article/view/523 (Accessed: 3 septiembre 2019)

Caicedo, D. and Porras, A. (eds.) (2010)Igualdad y no discriminación: el reto de la diversidad, Serie Justicia y derechos humanos. Ministerio de Justicia, Derechos Humanos y Cultos, Quito.

Cho, S. (2013) Post-Intersectionality: The Curious Reception of Intersectionality in Legal Scholarship, Du Bois Review: Social Science Research on Race, 10[online]. Available at:https://doi.org/10.1017/S1742058X13000362 (Accessed: 19 julio 2019)

Cho, S., Crenshaw, K.W., McCall, L. (2013) Toward a Field of Intersectionality Studies: Theory, Applications, and Praxis,Signs:Journal of Women in Culture and Society, 38 [online]. Available at: https://doi.org/10.1086/669608 (Accessed: 28 mayo 2019)

Arenas, M.(2013) At the intersection of feminist and disability rights movements. From equality in difference to human diversity claimsinBarnartt, S.N., Altman, B.M. (eds.) Research in Social Science and Disability, E-book library [online]. Available at: https://doi.org/10.1108/S1479-3547(2013)0000007004 (Accessed: 16 mayo 2019)

Erevelles, N. and Minear, A. (2010) Unspeakable Offenses: Untangling Race and Disability in Discourses of Intersectionality. Journal of Literary \& Cultural Disability Studies, 4 [online]. Available at: https://online.liverpooluniversitypress.co.uk/doi/10.3828/jlcds.2010.11?mobileU $\mathrm{i}=0$ \& (Accessed: 16 mayo 2019)

La Barbera, M. (2017) Interseccionalidad = Intersectionality. EUNOMÍA. Revista en Cultura de la Legalidad, 12 [online]. Available at: https://doi.org/10.20318/eunomia.2017.3651(Accessed: 16 mayo 2019)

Larson, E., George, A., Morgan, R. and Poteat, T. (2016) 10 Best resources on... intersectionality with an emphasis on low- and middle-income countries. Health Policy Plan, 31 [online]. Available at: https://academic.oup.com/heapol/article/31/8/964/2198131 (Accessed: 23 mayo 2019)

Lawson, A. (2011) Disadvantage at the Intersection of Race and Disability: Key Challenges for EU Non-Discrimination Law in Schiek and Lawson (eds.) European Union Non-Discrimination Law and Intersectionality Investigating the Triangle of Racial, Gender and Disability Discrimination. Routledge. E-book library [online]. Available at:https://www.routledge.com/European-Union-NonDiscrimination-Law-and-Intersectionality-Investigating/LawsonSchiek/p/book/9780754679806 (Accessed: 21 mayo 2019) 
MacKinnon, C. (2013) Intersectionality as Method: A Note. Signs: Journal of Women in Culture and Society 38 [online]. Available at: https://www.journals.uchicago.edu/doi/10.1086/669570(Accessed: 15 mayo 2019)

McCall, L.(2005) The Complexity of Intersectionality. Signs: Journal of Women in $\begin{array}{llll}\text { Culture and } & \text { Society } & \text { [online]. } & \text { Available }\end{array}$ at:https://www.journals.uchicago.edu/doi/10.1086/426800 (Accessed: 3 septiembre 2019)

Meekosha, H. and Shuttleworth, R.(2009) What's so 'critical' about critical disability studies?Australian Journal of Human Rights 15 [online]. Available at: https://www.tandfonline.com/doi/abs/10.1080/1323238X.2009.11910861 (Accessed: 17 julio 2019)

Meekosha, H. and Soldatic, K. (2011) Human Rights and the Global South: the case of disability. Third World Quarterly. 32 [online]. Available at: https://doi.org/10.1080/01436597.2011.614800 (Accessed: 19 julio 2019)

Minkowitz, T. (2010) El Artículo 12 de la Convención Sobre los Derechos de las Personas con Discapacidad - Consideraciones Para Su Implementación. Social Science Research Network[online]. Available at: https://papers.ssrn.com/sol3/papers.cfm?abstract_id=2037464 (Accessed: 17 julio 2019)

Naciones Unidas, Asamblea General. (2017) Informe de la Relatora Especial sobre los

Derechos de laspersonas con discapacidad A/HRC/34/58. 34 periodo de sesiones Consejo de Derechos Humanos [online]. Available at: https://www.ohchr.org/SP/Issues/Disability/SRDisabilities/Pages/Reports.aspx (Accessed: 2 abril 2019)

Portocarrero, A., Juanola, L., Arana, L., Gómez, A., Munévar, D., Feltrin, R.Tait, M.(autors)

and Revollar, T. (ed) (2014)Recomendaciones para la transversalización de la Inclusión Social y la Equidad en la docencia y la investigación[online]. Available at: https://www.lai.fuberlin.de/disziplinen/gender_studies/miseal/publicaciones/pub 9/index.html (Accessed: 3 septiembre 2019)

Sommo, A. and Chaskes, J. (2013) Intersectionality and the disability: Some conceptual and methodological challengesin Barnartt, S. and Altman, B. (Eds.)Research in Social Science and Disability. Emerald Group Publishing LimitedE-book library [online] Available at: https://www.emerald.com/insight/content/doi/10.1108/S14793547(2013)0000007005/full/html?skipTracking=true (Accessed: 8 agosto 2019)

Yuval-Davis, N. (2015) Situated Intersectionality and Social Inequality. Raisons Politiques. 58 [online] Available at: https://www.cairn.info/revue-raisonspolitiques-2015-2-page-91.htm\# (Accessed: 21 mayo 2019) 
Zota-Bernal, A. (2015) Incorporación del análisis interseccional en las sentencias de la Corte IDH sobre grupos vulnerables, su articulación con la interdependencia e indivisibilidad de los derechos humanos. Eunomia. 9 Available at:https://erevistas.uc3m.es/index.php/EUNOM/article/view/2803 (Accessed: 14 mayo 2019)

\begin{tabular}{|l|} 
Table No. 1 \\
MATRIX OF ANALYSIS THE DISABILITY SINCE INTERSECTIONAL \\
PERSPECTIVE \\
\hline Situation / case / example: \\
\hline Characteristics of source analyzed: \\
\hline Objective of the source analyzed: \\
\hline Characterization of the context in which the situation occurs: \\
\hline Overview: \\
\hline SITUATED ANALYSIS - DEFINING THE SITUATION UNDER STUDY \\
\hline Findings related to the Intersectional Perspective \\
\hline Findings on asymmetric relationships and traditional or heteronormative practices \\
\hline APPRECIATE NARRATIVES, EXPERIENCES AND WAYS \\
IN WHCH PEOPLE'S VOICES ARE RECOGNIZED \\
\hline Findings related to the Intersectional Perspective \\
\hline Findings on asymmetric relationships and traditional or heteronormative practices \\
\hline TO IDENTIFY INEQUALITY AXES LINKED TO THE OBJECT OF STUDY \\
BETWEEN AXES OF INEQUALITY \\
\hline Findings related to the Intersectional Perspective \\
\hline Findings on asymmetric relationships and traditional or heteronormative practices \\
\hline Findings related to the Intersectional Perspective \\
\hline Findings on asymmetric relationships and traditional or heteronormative practices \\
\hline
\end{tabular}


Annex 2

KEY QUESTIONS TO DRIVE THE ANALYTICAL EXERCISE

\section{SITUATED ANALYSIS - DEFINING THE SITUATION UNDER STUDY}

- When defining or identifying the situation under analysis, how is the heterogeneity inherent in the contexts and situations to which persons with disability are exposed recognized?

- Does the recognition of the situation to be analyzed include a critical review of the particular environments and situations in which persons with disability participate on a daily basis?

- Does the contextual analysis include aspects related to social determinants and inequalities (socio-economic and political context, multidimensional poverty, decent work, environmental factors, access to health services and quality care, inclusive education, barriers, opportunities and resources available in the environment for access and enjoyment of rights, social and community support network)?

\section{APPRECIATE NARRATIVES, EXPERIENCES AND WAYS IN WHICH PEOPLE'S VOICES ARE RECOGNIZED}

- Are particular experiences of Person with Disability recognized and valued for analysis, according to the context in which they live?

- Are multiple and heterogeneous forms of participation of the Person with Disability recognized?

- Through what mechanisms do they introduce alternative forms of communication, so that people with disability are aware of their interests and express their voice?

- Is there recognition of the importance of defining support systems or types of support tailored to people and built through their active participation?

\section{TO IDENTIFY INEQUALITY AXES LINKED TO THE OBJECT OF STUDY}

- Are other axes of inequality identified beyond those prioritized by institutionality?

- For which persons with disability are the measures aimed (all without discrimination or only for certain groups and/or persons in particular)?

- What kind of approaches (rehabilitative, social, human rights) are used? What kind of measures are privileged? What situations are left out or included as an exception?

- In what scenarios, at what times, under what conditions and for what purposes are the axes of inequality analyzed?

\section{TO UNDERSTAND THE SPECIFIC RELATIONSHIP BETWEEN AXES OF INEQUALITY}

- What kind of particular relationship can be interwoven when analyzing situations of inequality that at first sight account for their complexity?

- What new intersections can be configured by including other axes of inequality in the analysis?

- What type of intersection is established when the commonly analyzed axes of inequality are revised according to age, place of residence, type of services and support available?

\section{TO DESCRIBE THE OPERATION OF OPPRESSIVE SYSTEMS}

- What are the most naturalized forms of discrimination that inhibit full warranty?

- Through what direct and indirect measures are the voice of the Person with Disability silenced, denied and conditioned?

- What kind of situations and support measures are privileged and institutionally justified when providing services to people with disability? 